\title{
Formulation of court interpreting models: A South African perspective
}

\author{
Samuel Joseph Lebese \\ Department of Linguistics and Modern Languages, University of South Africa (UNISA), South Africa \\ Email: lebessj@unisa.ac.za
}

\begin{abstract}
In South Africa there are no models of court interpreting to serve as a guide for court interpreters when performing their task. This is because there is no proper definition of the role of a court interpreter. Models of court interpreting define and describe the process by stating what court interpreters are actually doing when carrying out their task. The absence of these models presents challenges to South African court interpreters as they are expected to follow international models which are formulated culturally, using English metaphorical language which differs from that of indigenous South African languages. As a result, the metaphorical language is likely to be misinterpreted by South African court interpreters as English is not their first language. The application of international models is likely to cause challenges when applied in the South African context, hence the need to formulate models of court interpreting which can be applied to the South African linguistic context. The study follows a qualitative research approach and uses multifaceted theoretical frameworks, namely descriptive translation studies (DTS), cognitive process analysis, and content analysis in collecting and analysing the data.
\end{abstract}

Keywords: court interpreters, cognitive teaching approach, court interpreting models, the role of court interpreters, court interpreters' workshops

\section{Introduction}

Research into court interpreting in South Africa has indicated, among other things, that poor performance by court interpreters is a result of a lack of proper training. This situation has led to scholars such as Steytler (1993: 221), Du Plessis (1997: 8) and Moeketsi (1999: 135-136) calling for an urgent need for proper training of court interpreters.

This study is a response to this particular call. The author and some colleagues in the Department of Linguistics and Modern Languages (Translation and Interpreting Studies) at the University of South Africa (Unisa) began to conduct workshops for the training of court interpreters from 2011 to 2012, offered as part of a community engagement project known as "Chance 2 Advance" which was initiated by the university in 2010. Community engagement refers to the voluntary outreach by academics and other university employees in response to the social, economic and political 
needs of communities. Some of the goals of this initiative are to promote the culture of learning within the community, bridge the knowledge gap between the educated and the uneducated, address skills development and social justice issues, and encourage lifelong learning. Through this initiative, the university aims to empower the community by offering workshops in different fields to help members acquire certain skills that will make them employable and improve the careers of those already in employment.

The workshops were presented at the university campuses in Pretoria (Gauteng province) and in Polokwane (Limpopo province). Later, these workshops were moved to the Diepsloot community centre in Gauteng province. The aim of the workshops was to improve court interpreters' existing skills and to help them develop more confidence and proficiency in interpreting. One way of doing this was to teach them to formulate models of interpreting for the South African linguistic context using the cognitive process approach.

Wilcox and Shaffer (2005: 135) observe that a model of interpreting demonstrates how interpreters perform their role and guides them towards improving their performance. It is from this point of view that South African court interpreters need to be familiar with different models of interpreting to enable them to understand their role and the implications of their task. This will enable them to define their role and perform their task satisfactorily, in accordance with the expectations of the legal fraternity as well as those of the recipients of the interpreting service. It has been argued by scholars that the interpreter may assume several roles during interpreting and that this may be subject to, among others, a variety of codes of ethics or other formulations, whether originating from within the judicial system, a professional association or elsewhere (Morris 1999: 1). The author takes cognisance of the fact that the role of court interpreters is a contentious issue among both international and local scholars. Angelleli (2004: 13) observes that interpreters have been prescribed and dictated to without the complexity of their role being understood, which has led to a distortion of the reality of interpreters' work. She states that this is evident from different settings in which interpreters work and the people for whom they interpret, the latter who impose different constraints and needs on the interpreted communicative events that interpreters facilitate. Such conduct results in the role of interpreters being subjected to constant change in order to satisfy those needs and constraints (Angelleli 2004: 13).

In South Africa, although the issue of the role of court interpreters has been researched and discussed by scholars such as Moeketsi (1999) and others, no approach has been suggested which could assist in better understanding the role of court interpreters. As a consequence, the current study aims to address this deficiency by asking court interpreters to describe and define the concept of 'interpreting' using their South African indigenous languages. In other words, they were made to think critically about the process they carry out when interpreting. This approach allows room for interpreters to express their opinions and experiences without fear of judgment. It is hoped that such an approach could ultimately lead to the formulation of court interpreting models which could be applied in the South African context and thus enable court interpreters to better understand their role during interpreting, thereby improving their confidence and proficiency.

The study follows a qualitative research method of investigation and is informed by multifaceted theoretical frameworks, namely descriptive translation studies (DTS), cognitive process analysis and content analysis. This research method and these theoretical frameworks are favoured in this 
study as Toury (1980: 80) observes that translation and interpreting practices are not merely the outcome of speculation, but are observational facts that take place in the real world and for which the DTS theoretical framework, among others, is able to account.

\section{Overview of models of interpreting}

In an interpreting setting in a courtroom, a situation arises where two or more courtroom participants are faced with the problem of being unable to communicate with each other because of their language differences. As a result, an interpreter is needed to facilitate communication between these individuals. Between these participants, there is always a need to share certain information and also to help the court to hear the matter brought before it for adjudication. During court proceedings, there is the likelihood that these parties may agree or disagree on certain shared information. In the event of this happening, there will be a need for parties to question and respond to one another's questions, be it directly or through legal representatives. However, even if they want to communicate among themselves and with the court, they are unable to do so because they do not understand one another's languages. The problem faced by these participants is an unavoidable reality which requires a solution. Intervention by someone with the ability to bring about mutual intelligibility is therefore needed in order to remedy this situation. The question, however, remains: Who is responsible for defining and describing the task in which this individual is involved? The next question that needs to be answered is: Who can best define the task performed by this individual?

In response to these questions, it is the author's contention that the person who carries out the task of interpreting is the one who can best define and describe the processes involved therein. However, as pointed out by Padilla, Bajo and Padilla (1999: 61), these processes are complex, are not purely linguistic, and must also be understood within their social, cultural and - above all - their psychological contexts. This understanding can therefore be shown by the individual who carries out the task of interpreting through a comprehensive analysis of this particular task. It is for these reasons that the author maintains and argues that the definition of the role and models of interpreting can best be described and defined by court interpreters themselves, as they are familiar with the interpreting process. They should not be dictated to by those who lack knowledge of what court interpreters actually do when involved in the process of interpreting.

This view is supported by Eighinger and Karlin (2001: 5) who observe that many of the definitions of interpreting and metaphors used to describe successful interpreting are at odds with what occurs in practice. It is the author's contention that this is due to the fact that these definitions are supplied by individuals who are not interpreters and, as such, cannot fully understand the process. Interpreters are in the best position to provide these definitions since they are involved in the process. Eighinger and Karlin (2001: 6) further maintain that interpreters must weigh up and manage their own ethics and values, and that such an approach will allow them to recognise their role. This way, the author contends, they can succeed as they would be guided by their understanding of the interpreting process which they carry out.

Wilcox and Shaffer (2005: 135) observe that models of interpreting have been developed over the years, from an early view in which the interpreter was seen as a passive mechanical conveyor of information much like a telephone, to more modern conceptions, such as communication-facilitator or bilingual-bicultural specialist, which acknowledge that interpreters are important agents in the process of interpreting. The authors maintain that 
interpreting is an active process of constructing meaning based on evidence provided by speakers, and is essentially about communicating. They further argue that models of interpreting are based on assumptions of how human communication works. As a result, they propose a cognitive process model of interpreting and explore the implications of this model for the preparation of interpreters and how interpreters function in their daily work (Wilcox and Shaffer 2005: 27-28). Angelelli (2004: 32) concurs with the view that interpreting is about communicating and states that "in a court setting the defendant, plaintiff or other officer of the court and the interpreter come together in the course of a trial to communicate about a specific issue, as well as to collect information about it". According to Angelelli (2004: 7), the basis of the role of interpreters is to facilitate communication. However, she observes that a discrepancy exists between the role that is prescribed for interpreters and that which unfolds in practice (Angelelli 2004: 2). This study is based on the latter, as court interpreters are asked to describe what they do in practice and to define the concept of 'interpreting' using their own South African languages. Mullamaa (2009: 148) endorses this approach and suggests that the role of the interpreter could be described through notions that help us better to grasp the multifaceted nature of the interpreter's task and identity, and that these two aspects could be introduced to analyse the interpreter's role. That is exactly the approach that this study endeavours to take, namely allowing court interpreters to define interpreting in terms of what they do in practice and not in terms of what they are taught. Through their definitions, the nature of an interpreter's task and identity can be analysed and more fully understood.

Colonomos (1992: 1) defines a model of interpreting as "a representation and description of the process an interpreter should complete in order to successfully, accurately and efficiently interpret a message from a speaker in a source language to an audience in a linguistically acceptable target language". She describes a variety of the following processing considerations: firstly, and most obviously, the model is a linguistic one as it addresses two languages; secondly, it is a cognitive model in the sense that it describes the mental process involved during an interpretation; thirdly, it is cultural as the model goes beyond the mere linguistic consideration of the two languages by addressing their respective cultural considerations; fourthly, the model is psychological as it examines the interpreter as an individual with his or her own perceptions, feelings and knowledge base, as well as the impact an interpreter may have on the communication process; finally, the model is cyclical as the interpreter continually goes through all stages of the process during interpretation.

Cokely (1992: 2) draws on some elements from Colonomos' definition above, and defines a model as "a hypothetical representation of a process or object, that serves to verbally or geographically display an event, object or series of events". Colonomos' model of interpreting is relevant to the cognitive process model as it considers aspects relating to the communication process, of which interpreting is one. Court interpreting is a method of communication in its own right and takes into account issues pertaining to two languages, considers aspects of culture, and considers the presence of the interpreter as having an influence on the nature of the communication between parties involved in the interpreting process.

In his discussion of models, Pöchhacker (2010a: 84-85) states that, in principle, models of interpreting can be envisaged for any of the purposes previously mentioned by Colonomos (1992: 2). He adds that, as is evident from the evolution of ideas regarding interpreting, the phenomenon is of such a complex nature that it eludes attempts at constructing a comprehensive predictive model. In his opinion, most models of interpreting are of a descriptive kind and are 
pegged to a particular level of analysis. In dealing with issues of models regarding their nature, form and purpose, Pöchhacker (2010a: 84) states that:

A model can be described as some form of representation of an object or a phenomenon. Models usually indicate the type and number of components which are assumed to form part of the object or phenomenon under study, and reflect the way in which the components fit together and relate to one another. In essence then, a model is an assumption about what something is like and how it functions, so that modelling can be regarded as a particular form of theoretical endeavour.

Pöchhacker's statement is relevant to this study, as the definitions and descriptions of the processes that court interpreters are involved in during interpreting become a representation of what they actually do when interpreting, which ultimately informs a model of interpreting. This aspect becomes clear as Pöchhacker (2010a: 85) further states that models can be used for various purposes of enquiry and that, as a basic form of theorising, they can express intuitive assumptions and ideas about a phenomenon. He supports the approach followed in this study and states that models constructed on the basis of more immediate observations and empirical data are used for the purpose of describing some aspects of reality and can be used for explaining how and why a phenomenon occurs (Pöchhacker 2010a: 85).

\section{The relevance of models for court interpreting}

Pöchhacker's (2010a: 85) sentiments described above become relevant for court interpreting, as through the process of defining or describing a model, an interpreting phenomenon can be explained. In other words, a person is able to account for the process of interpreting in terms of how interpreting is carried out, and also for all the elements that are involved in the process itself. For example, the model of interpreting explains interpreting as a form of communication because it involves aspects of two languages and some elements of culture.

The discussion of the origins and developments of interpreting models in this study is relevant as it helps to explain exactly what South African court interpreters are doing when interpreting. In other words, one needs to understand the process involved during interpreting because interpreting is about communicating messages (Wilcox and Shaffer 2005: 135). The models of interpreting are therefore used in describing the interpreting process and they serve as guidelines or directives for interpreters. The formulations of these models are based on the role descriptors that clearly describe what court interpreters do during the process of interpreting (Wilcox and Shaffer 2005: 135). This view is supported by Roy (1993: 347) who maintains that models of interpreting were formulated from metaphorical descriptions of the role of interpreters because these descriptions were used in understanding what the interpreters were doing. Lakoff and Johnson (1980: 133) concur with this view and state that metaphorical terms determine the way phenomena are conceptualised and they serve as a way of understanding.

Setton (2013: 365) supports the views of Wilcox and Shaffer (2005: 135) but approaches models of interpreting from a different point of view, stating that models fall into two categories, namely relational and cognitive models. Relational models deal with patterns of interactions in interpreted events, and focus on the social and behavioural determinants of the activity which embed interpreting within a broader framework such as human social 
communication or even a general theory of activity. Setton (2013: 365) further states that relational models draw attention to the interpreter's role, and this role is not always straightforward. This is especially so in the less conventionalised and more frequent face-toface settings and configurations of community, public service, legal or media interpreting. On the other hand, cognitive models focus on the mental activity of the individual interpreter, considering issues of memory, attention and bilingual neurolinguistic organisation or processing capacity (Setton 2013: 365).

Roy (1993: 131) observes that, as a result of the changing circumstances, one model was replaced by others. To date, legal practitioners and interpreting scholars around the world still dispute which is the best, most appropriate and acceptable model of interpreting (Mullamaa 2009: 145). In the following section, different models of interpreting are discussed by legal practitioners, interpreting scholars and practitioners of interpreting in general, including those who practise in the courtroom setting.

\subsection{The helper model}

According to this model, sign language interpreters (for the deaf and hearing impaired) were regarded as helpers by the court, and even in other settings, in defining and describing the role of such interpreters. Bar-Tzur (1999: 1) observes that the helper model came about before interpreting was even recognised as a profession, where hearing children of deaf adults acted as interpreters to help their parents communicate with those who could hear. These children were forced into learning sign language at home in order to be able to communicate with their deaf parents. Later, clerics or social workers also acted as interpreters for deaf people because a few of the former had a cultural obligation to attend events for the deaf. These interpreters often felt that they brought salvation to many other cultures and minorities, ultimately giving the world direction. They thought of themselves as essential for deaf people's functioning, while deaf people felt that they needed these interpreters' help in order to survive in the world (Bar-Tzur 1999: 1). These interpreters used the consecutive mode of interpreting, which means that the interpreter waits for the speaker to complete an utterance before interpreting, and they would often summarise and edit as they saw fit. In order to help, interpreters would share confidential information with people in authority (Bar-Tzur 1999: 1). A practice such as this is in conflict with the National Association of Judiciary Interpreters and Translators' (NAJIT) "Code of Ethics and Professional Responsibilities" which states that interpreters are not allowed to divulge confidential information obtained during proceedings (NAJIT 2005).

Although this model was defined and described by those not personally involved in interpreting, interpreters viewed their role in this way. An important aspect that needs to be considered with respect to these interpreters is that they did not receive any training or interpreting qualification, and this may have influenced their decision to agree that their role was that of a helper. Lack of training regarding communication processes - such as the consideration of working with two languages, the fact that interpreting is communication, and that cultural aspects need to be considered - may have had an influence on their perception of their role. In terms of their selfperception as helpers, it would seem that these interpreters defined their role in this way because they offered help to the deaf by way of intervention at a time when there was a breakdown of communication. However, there is nothing that indicates that they consider the interpreting process as communication by, for example, taking into account the more complex aspects pertaining to communication, as indicated in the discussion above. 
Clifford (2004: 94) concurs with Bar-Tzur (1999: 1) and states that deaf people have long relied on "helpers" to communicate with the hearing world. These helpers were often hearing friends and family members who had some knowledge of both sign language and the spoken language in question. Helpers were free to act as they saw fit and many offered advice, made decisions for the deaf person, shared confidential information with authorities if they thought it was in the deaf person's best interests, and selected and edited the information they interpreted according to their perception of the deaf person's understanding. The helper's behaviour underscored an attitude that the deaf were incapable of making decisions and taking care of themselves, and this attitude was sometimes internalised by the deaf themselves with obvious negative repercussions (Roy 1993: 127). The helper was a role which allowed for the extreme personal involvement of interpreters.

Renmen's (1999: 1) view of help is that when you help someone, you may inadvertently take away from people more than you can ever give them, and this can diminish their self-esteem, sense of worth, integrity and wholeness. This statement supports Roy's (1993: 127) contention, mentioned above, that the helper's behaviour implies that the deaf are incapable of autonomy. This is indicated, as Roy (1993: 127) observes, by the fact that in other instances interpreters would take decisions on behalf of those for whom they were interpreting. However, in a court interpreting setting, Renmen's view of help is the opposite as, in practice, people who are unable to communicate in the language used during court proceedings rely solely on interpreters in order to communicate. The court interpreter functions as the saviour of this situation. Two questions now arise: How do people who receive interpreting services view the interpreter who acts in order to remedy the situation where there is a communication breakdown? Would the interpreter be viewed as the helper who will "save" the situation? In South African courts, one often hears magistrates asking the accused persons whether they would need the "help" of an interpreter. From such utterances, it would seem that some magistrates do indeed view the interpreter's role as that of a helper.

The definition of the role of the court interpreter as a helper was later declared inappropriate as it denied the people involved any autonomy. It led to the view that there was no distinction between a helper and an interpreter, and as interpreting began to be recognised as a profession, there was a sharp move away from the helper model (Clifford 2004: 94). Two key events were cited as the hallmarks of this transition: firstly, the founding in 1964 of the Registry of Interpreters for the Deaf, the principal professional organisation that represented sign language interpreters in the United States; and secondly, the publication in 1965 of the Registry's first manual for interpreters, called "Interpreting for Deaf People" (Clifford 2004: 94).

These two events signalled the advent of a new level of professionalisation, one that was incompatible with the unequal status implied in the notion of the term "helper". According to the Registry, the relationship between interpreter and client had to be one between equals. As such, there were calls to reject the emotional and personal involvement of the helper model, and to strive instead to regard the interpreter as neutral, invisible and uninvolved. This led to the interpreter being described metaphorically as an inanimate device or a machine, such as a telephone wire that served as a conduit for information flow (Clifford 2004: 94-95). Because the profession of interpreting had to consider models of professional behaviour other than that of a helper, this led to the origin of the "conduit model" (Clifford 2004: 95) which is discussed in the following section. 


\subsection{The conduit model}

According to Lee (2009: 36), the first leading case to introduce the conduit model to Australia was Gaio v R (1960) 104 CLR 419. In this case, the High Court judges define the interpreter as a "conduit" because the interpreter has to translate (i.e. interpret) everything. Morris (1999: 8) refers to this model as the "invisible pipe" model. The legal practitioners perceive the interpreter to be an "invisible pipe", with words entering in one language and exiting completely unmodified in another language. In this model, the interpreter is a mechanical instrument that can be used as the court deems fit (Morris 1999: 8). In the conduit model, the court interpreter is not expected to provide or ask for clarification and, as a result, judges believe that this would be a way of avoiding hearsay when obtaining evidence through the interpreter (Lee 2009: 36). This model was developed as a technical solution to avoiding subjective elements as the interpreter was merely to serve as a conduit pipe, providing semantic equivalents from one language to another (Laster and Taylor 1995: 11). The conduit model provided a way of distancing the emerging professional interpreter from the unethical and unsatisfactory practice of the "bad old days" (Laster and Taylor 1995: 12).

According to Bar-Tzur (1999: 2), the conduit model was developed with the intention of avoiding the injustices that stemmed from the helper model and to return control to deaf people. Interpreters felt that they had to be invisible, neutral and uninvolved, and they saw themselves only as an instrument for information flow. The conduit model brought with it two important aspects, the first being the birth of standards and ethics for interpreters, and the second that deaf people were receiving representations of the words and not of interpreters' subjective reformulation of the meaning (Bar-Tzur 1999: 2).

In South African courts, the conduit model could cause communication problems because speakers, mostly adult participants, tend to use metaphorical expressions that are specific to their primary language in their communication. If these metaphors are not fully understood by the interpreter, they could lead to stilted communication because they usually do not have equivalents in the English language. Even if interpreters seem to accept the conduit pipe role, there is a great possibility that they might be seen to be deviating from such a role when, in the interests of clarity, they provide explanations for certain utterances. Steytler (1993: 208) supports this statement and argues that interpreters do not necessarily interpret their role as simply being a conduit for verbal information, but that they often redefine their role when unforeseen difficulties arise. For example, there are instances where legal concepts do not have equivalents in the target language, and the interpreter may need to explain these to the participants. While such action might lead to successful communication, it would conflict with the conduit model which would not support the interpreter's intervention in providing explanations.

The conduit model was challenged by courts and tribunals as well as by interpreting scholars and practitioners for its risks of message distortion and miscommunication. The contention is that a court interpreter is a facilitator of communication and not merely a translation machine. The courts seem to have realised that interpreting is not only about translating messages from one person to another, but also that issues of communication need to be taken into account. In other words, interpreting has to be viewed as a means of communication between people who do not share the same language. 
There have been landmark cases in Australia that have set the tone for redefining the role of the interpreter in legal settings. According to Lee (2009: 37), the cases of Gradidge v Grace Bros Pty Ltd (1988) 93 FLR 414 and Perera v Minister for Immigration and Multicultural Affairs (1999) 92 FCA 507 prescribed the role of the court interpreter as removing barriers and placing the non-English speaker in a position that would be as close as possible to that of an English speaker. By implication, this means that the court interpreter cannot function merely as a language converter, but needs to be fully involved in the process of communication. His or her involvement means making accurate communication possible by removing any barriers that may compromise understanding. The conduit model prevents this from happening and, as a result, the court deemed it fit to reject this model and replace it with the communication facilitator model which is discussed below.

\subsection{The communication facilitator model}

In her investigation of the role of the court interpreter, Berk-Seligson (2006) found that in many legal proceedings, judges and attorneys perceive the role of the interpreter to be that of a facilitator, intercultural mediator and even advocate. They are of the view that the role of the interpreter is to facilitate communication where one party is not conversant in the language of the court. Lee (2009: 38) observes that while the term "facilitator of communication" is used as the appropriate role descriptor for court interpreters in some of the literature, other researchers consider any facilitative role to be inappropriate, and compare it to filtering or embellishment. While the helper model denies the deaf autonomy by allowing too much involvement by the interpreter, the conduit model on the other hand denies the court interpreter the right to make communication possible by restricting him or her to a word-for-word interpretation. Therefore, the communication facilitator model seems more appropriate for court interpreting because it views interpreting as communication. However, this model was also criticised for its facilitative role, according to Lee (2009: 38), and was replaced by the bilingual-bicultural model which will be discussed in the following section.

\subsection{The bilingual-bicultural model}

By the early 1980s, most of the descriptions of interpreters acknowledged that interpreters must be sensitive to the fact that they communicate across cultures as well as between languages (Roy 1993: 134). This was based on Cokely's (1992: 140) notion that "before an individual can interpret between two languages or cultures, he must be bilingual and bicultural where he must be aware of regional or dialectal differences in language, nonverbal differences, and different attitudes toward time, different forms of personal address and other differences".

According to Bar-Tzur (1999: 2), this model came about because interpreters sought to understand the cultures of both participants involved in communication in order to find equivalence as far as possible so that both sides are able to see the other's perspective. In doing so, interpreters become culture brokers (Bar-Tzur 1999: 2). This could be visualised as a double-helper model, where both deaf and hearing people require help and the interpreter is the one to give it to them. Bar-Tzur (1999: 2) sees the positive and the negative aspects of this model: the positive aspect is that interpreters can find greater semantic equivalence, and the negative aspect is that interpreters may overstep the bounds of their interpreting role by trying to be experts in everything. 
Unlike the helper-, conduit- and communication facilitator models, the bilingual-bicultural model takes the role of the court interpreter further. This model cautions that court interpreters need to consider issues of culture when interpreting for people who speak different languages. Language is embedded in culture and unless one understands the cultural aspects of a particular language, there is the risk of miscommunication. What something may mean in one language may mean something different in another. It is therefore important that the court interpreter has knowledge of the languages as well as the culture in which he or she interprets. If not, the likelihood that there will be miscommunication is strong. However, scholars such as Bar-Tzur (1999: 2), Kondo (1990: 60), and Gonzalez, Vasquez and Mikkelson (1991: 240) criticised the fact that the interpreter should act as a cultural mediator as he or she might be seen as assuming the role of cultural expert, which could be viewed as overstepping the role of interpreting. Kelly (2000: 132) concurs with this view as there are dangers in the cultural intervention of the interpreter and especially the court interpreter. She suggests that the role of the court interpreter be redefined rather than be regarded as the bilingual-bicultural mediator. It was the criticism above that led to the replacement of the bilingual-bicultural model with the language facilitator model, the latter which is discussed below.

\subsection{The language facilitator model}

Lee (2009: 37) explains that a court interpreter is a "language facilitator" or "language conduit" whose participation allows an individual who does not speak or understand English (or the language of the court proceedings) to participate meaningfully in a judicial proceeding.

An interpreter conveys the meaning of a word or group of words from a source language into the target language. Colloquial expressions, obscene or crude language, slang, cultured or scholarly language all have to be conveyed in accordance with the usage of the speaker. A court interpreter's job is not to tone down, improve or edit any statements; he or she must maintain the same register, level and style of the language spoken (Lee 2009: 37).

The language facilitator model is similar to the model of communication facilitator because both models call for successful communication. The meaning and understanding of messages are crucial points according to these models. In a courtroom situation, it is important for participants to understand the meaning of any utterance in order to be able to participate fully in the proceedings. If interpreters carry out their duty in this way, the chances of misunderstandings between the parties involved will be reduced. Like other previous models, the language facilitator model was also challenged by scholars like Hale (2008: 100), who considered any facilitative role by the interpreter to be inappropriate and compared it to filtering or embellishment. Lee (2009: 38) supports this view and states that, in court interpreting, provision of opinion or extra information is generally regarded as overstepping the bounds of the court interpreter's role. The criticism of this model, as well as others preceding it, led to court interpreters defining their role and also formulating their own models of interpreting. The following section examines how court interpreters have defined their role.

\subsection{The channel or bridge model}

According to Roy (1993: 130), court interpreters have used metaphorical language to describe their role as that of "the person in the middle". They assert that they serve as a kind of channel or bridge through which communication between two people can occur. Court interpreters see 
themselves as a means to communicate, and this concept of 'connection' is clear in the words "channel" or "bridge". What this channel does is complex: interpreters are required to reproduce a message from one speaker to another faithfully, accurately and without emotional or personal bias entering into the interpretation. In other words, interpreters must simultaneously render messages without changing the message's intent, and they must do so with exceptional accuracy while maintaining a stance of impartiality and neutrality (Morris 1999: 9). Specifically, interpreters may not introduce or change topics, ask questions of their own, interject their opinion or give advice, and most importantly, they must keep the entire transaction confidential. The performance of this role has been compared to a machine, a window, a bridge and a telephone line, among other metaphors, in trying to compress the complexity of the role into a simple, singular analogy (Roy 1993: 133). This model seems to be similar to the conduit model in certain respects because, like the conduit, the court interpreters view themselves as a means of making communication possible. However, in the channel or bridge model there is a greater emphasis on accuracy which is in line with the communication facilitator- and the bilingual-bicultural models. This model eschews the element of personal involvement and stresses the qualities of impartiality and neutrality in the interpreter.

The discussion in this section has provided an overview of how models of interpreting were formulated. It shows that these models were formulated according to how the role of interpreters was viewed by scholars and also by judges before whom interpreters were performing their duty. This model formulation was done by using different metaphorical language to define and describe the task which interpreters were carrying out during interpreting. All court interpreters were expected to abide by the model applicable at the time because the model was made a rule of law. These models served as guidelines for all court interpreters who were expected to perform according to how their role was conceptualised and defined.

\section{Workshops for training court interpreters}

\subsection{The profile of the workshop participants}

Invitations for the workshops held at Unisa were sent to principal court interpreters who were asked to distribute these invitations among their subordinates and to make arrangements for those who were interested in attending. The invitations were well received and there was a good response from interpreters who indicated their willingness to attend. The first workshop was presented on the university campus from 31 January to 4 February 2011, and was attended by practising court interpreters and novice interpreters. There were 17 participants registered for the workshop but only 12 attended. The second workshop was presented on the university campus from 10-12 August 2011. In this workshop, 20 court interpreters were expected but only 10 attended. The third workshop was presented on the university campus from 22-24 August 2011. This workshop targeted about 20 participants because, after the first two workshops, the good news regarding the quality of the workshops had spread widely among court interpreters all over the country. We received many calls from interpreters in different provinces who were interested in attending. The third workshop was attended by 31 participants. The fourth workshop was held from 26-28 September 2011 at the Unisa campus in Polokwane. It was attended by 59 participants who were practising court interpreters in Limpopo province. Its success in terms of participation resulted partially from the support given to court interpreters to attend the workshop by the Department of Justice and Constitutional Development (DoJCD) regional office in that province. 
The workshops were attended by practising court interpreters who were appointed on a permanent basis in the DoJCD, and also by freelance foreign language court interpreters who served in the DoJCD on a casual basis. Among the freelance interpreters, one was a Unisa student who was studying towards a BA Honours in Linguistics (Translation and Interpreting Studies). The court interpreters who attended this workshop were from magistrates' courts in East London, Gauteng, the Free State, Limpopo, Mpumalanga and North West provinces. Looking at the numbers of court interpreters who attended these workshops, and also the fact that they were from different magistrates' court offices in different provinces, it may be said that this was a good representation of court interpreters across the country. Among them were interpreters who could interpret from English and Afrikaans into other South African languages, and vice versa. Others could only interpret from English into other South African languages. Foreign language court interpreters had no knowledge of Afrikaans and were interpreting from English into their respective foreign languages.

The different groups of participants included a female inspector of court interpreters, principal court interpreters, senior court interpreters, junior court interpreters, and beginner court interpreters. The participants attended workshops on different dates and at different venues. These court interpreters had served in the DoJCD for different periods, ranging from one year to more than 20 years. Many of them held the qualification of a matric certificate and only three had obtained a diploma in legal interpreting from Wits University. Few were in possession of diplomas and degrees from different institutes which were not related to court interpreting.

\subsection{The design of the workshops}

The workshops were structured in such a way that the aspects covered were prioritised according to the author's experience and research in the field of court interpreting, which was appropriate for the teaching and training of court interpreters. The workshops covered the following aspects:

- interpreting theory

- theory of interpreting process: Giles' model and turn-taking

- modes and types of interpreting

- components of the interpreting situation

- note-taking and memory skills

- the role of interpreters in general and of court interpreters

- public speaking

- interpreters' professional ethics in various settings.

Participants were also subjected to practical interpreting which was conducted in a moot court. This was done to see if participants could implement the theory that they were taught. The author's experience is that interpreting cannot only be taught theoretically; putting into practice what one is taught in theory is of utmost importance.

\subsection{Facilitation approach}

The approach to teaching was such that court interpreters were made to think critically about the practical aspects of interpreting, rather than merely being fed information. As a result, participants were encouraged to draw from their own practical experiences and understanding 
of the process involved during interpreting. This approach was based on the author's experience as a former court interpreter in the DoJCD, his research conducted in the discipline of court interpreting, and his experience in teaching translation and interpreting at the university. The teaching began with the participants being asked what their view was regarding the models of interpreting and how these models were impacting their interpreting task. For a moment, all of the participants were silent. They were then asked whether they knew about the models of interpreting and they confirmed that they did. The participants were then asked what they understood by the concept of 'interpreting' and to define this concept in their own South African languages, with the focus on the process they use during interpreting. Lesch (2011:359) refers to this approach as a dialectical relationship towards research, done by the trainer in collaboration with the learners. He asserts that it should be considered as a way of empowering and introducing the learner to the theory of interpreting. This approach gives participants the opportunity to develop their understanding by exchanging logical arguments when presenting their different definitions. Furthermore, Lesch (2011: 359) views this approach as important and states that "without any theoretical sessions much can be gained from the practice-oriented instruction by experienced interpreters whom one can regard as masters of the craft".

Pöchhacker (2010b: 3) refers to the facilitation approach as "evidence-based teaching", and mentions that it is extremely important as it builds and extends the knowledge base on which sound instructional practices rest. The definition of this concept would also cover the role description provided by the interpreters themselves of what they do in practice. This is evidence-based, and this role description would finally lead to the formulation of the model.

In order for the participants to respond to the question of what their views are regarding the models of interpreting and how these models were impacting their interpreting task, they were then given the following scenario: "If your grandmother were to ask you "What is it that you do when you are interpreting?', how would you define the process of interpreting to her?'. They were asked to work in groups, where the participants in each group shared the same language, in order to respond to the question. This was done in order to have a good representation of each language from different participants who were from different provinces, and also to ascertain whether the participants understood what is involved in the interpreting process. This is crucial because if interpreters understand the process, they are in a better position to perform quality interpreting. However, it is acknowledged that even if they understand the process, it would not be unusual to find instances where there are deviations from the application of the process. These could be instances where court interpreters are ignorant of their task and compromise it by encroaching on the duties of other court officials, like magistrates (Lebese 2011: 343). However, if the process is better understood, such deviations could be minimised.

\section{Participants' responses}

The following section contains responses provided by participants to the question posed above, i.e. "If your grandmother were to ask you 'What is it that you do when you are interpreting?', how would you define the process of interpreting to her?".

\subsection{Sepedi-speaking participants}

In answering this question, the participants gave definitions in their own languages. Some of those who were Sepedi (Northern Sotho) speakers agreed that, to them, interpreting meant go hlalosa 
se se boletšwego ka leleme le lengwe ('to explain what was said in another language'). They argued that when a person interprets, he or she explains to the speaker of the target language what the speaker of the source language has said. They elaborated by saying that when a person interprets, he or she is explaining the speaker's words to the listener. They argued that if this is not the case, then why would the interpreter speak after the speaker? This argument remains valid if we agree that the interpreter first listens to the speaker and thereafter interprets what the speaker has said. This definition relates to the conduit model because the message is made available in another language. The first issue to be considered here is that the term "explain" is problematic. There is a possibility that the interpreter might explain what he or she understands and this might not be what the speaker intended. This definition also does not encompass consideration of issues of culture and making the communication understood by the target language speaker, as suggested by the scholars in the earlier discussion.

Other Sepedi speakers agreed that in the interpreting process ofetišetša se se boletšwego ka mo lelemeng le lengwe ('you convey what was said into another language'). They argued that the person hears what is being said by the speaker and passes it on to the speaker of the other language so that he or she can understand what has just been said. These participants' argument was based on the fact that, as an interpreter, a person facilitates communication between two people who do not speak the same language. This definition clearly fits the conduit model as the interpreter acts like a pipe because he or she interprets the message into the other language.

Sepedi speakers from another session answered the question by saying that interpreting is go bolela se se boletšwego ka polelo ye nngwe ('to say what was said into another language'). These participants mentioned that the speaker says something and the interpreter tells the other person what the speaker has said.

Other Sepedi-speaking participants defined the interpreting process as go boeletša mantšu a seboledi ka polelo ye nngwe ('to repeat the words of the speaker into another language'). These participants explained that, to them, interpreting meant repeating spoken words in a different language. The definition provided here also fits the conduit model as the interpreter repeats what was said but in the target language.

Another group of Sepedi speakers defined interpreting as go fetiša molaetša/bohlatsi magereng ga mmoledi le molatofatšwa ka ntle le go oketša goba go fokotša ('to convey the message/evidence between the speaker and the accused without adding or subtracting'). This definition also fits the conduit model, which holds that the interpreter should not add or omit any information in conveying the message. It also approximates the bridge or channel model.

\subsection{Southern Sotho-speaking participants}

Southern Sotho-speaking participants defined interpreting as mokena-dipakeng malemeng a fapaneng hobe le molaetsa o nepahetseng, o sa oketse le ho fokotsa ('a go-between for different languages so that there must be a correct message, without adding or subtracting'). This definition also resembles the channel or bridge model, where an interpreter acts like an instrument that makes communication possible. 


\subsection{IsiNdebele-speaking participants}

The participants from the isiNdebele language group defined interpreting as ukundlulisa umlayezo o vela kumangali ukuya ku msolelwa ngaphandle ko ku ongeza no ku khipa inkulumo yabo ('to convey the message from the complainant to the accused without adding to or subtracting from their speech'). The definition provided here is the same as that given by the final group of Sepedi-speaking participants in section 5.1.

Another definition of interpreting given by this group was kurhelepa abantu abeza ekundleni yemilandru ukuzwisisa konke okwenzekako, ukudlulisa imilayezo nokwenza abantu bazizwe bakhululekile ('to assist people coming to the court that deals with offences to understand all that is happening, to convey messages and to make people feel free'). This definition encompasses the helper-, the conduit- and the communication facilitator models. It is also worth noting that the definition also contains the element of "making people feel free" which may be associated with the helper model.

\subsection{Xitsonga-speaking participants}

Xitsonga-speaking participants defined the interpreting process as $\mathrm{ku}$ hlamusela hi ririmi ri $n$ 'wana ('to explain in another language'). Their explanation of this process was that the interpreter explains to the listener what the speaker has said because the listener does not understand the language of the speaker. Another definition of interpreting given by this group was muhlamuseri wa timhaka ('the one who explains messages' - this English definition was provided by the group itself). This definition relates to the explanation provided by some of the Sepedi-speaking participants.

\subsection{Setswana-speaking participants}

Participants who were Setswana-speaking defined interpreting as go fetisa molaetsa, o o fetisetsa go yo a sa utlwisiseng puo e e buiwang ('to convey the message to someone who does not understand the language that is spoken'). Another Setswana-speaking participant defined interpreting as go thalosa molaetsa go tswa mo lelemeng le lengwe go ya go le lengwe ntle le go fokotsa le go oketsa ('to explain the message from one language into another language without subtracting or adding'). This definition is similar to that provided by some of the Sepedi-speaking participants.

\subsection{IsiZulu-speaking participants}

The participants from the isiZulu group defined interpreting as $u k u$ ncedisa abantu aba cabanga ukuthi inkundla yindawo ethusayo, ukuthi behlise umoya bakhululeke ('to assist those who think that court is a place that makes people nervous, so that they can relax'). This group gave a further definition of interpreting as ukucacisela abavakashi okwenzekalayo enkundleni ('to explain to the court visitors what is happening in court'). The other definition of interpreting given by this group was uhlathulula kolwimi oluhlukene ukuya kolunye ('you explain from a different language into another'). The definitions provided here are similar to those of the Sepedi- and IsiNdebele-speaking participants. However, the first and second definitions have an additional element: the role of the interpreter in helping to reduce anxiety in the speakers 
and familiarising them with court procedures, i.e. helping the speakers to feel comfortable in a strange situation.

\subsection{IsiXhosa-speaking participants}

IsiXhosa-speaking participants defined interpreting as isithethantonye/ntetha solwimi ukucacisela omnye umntu ('a person who conveys or makes a repetition for another person in a language that one understands' - this English version was given by the group itself). A qualified translator translated the phrase as "a person who substitutes a meaning using another language to explain that meaning to someone else". This definition relates to that provided by the Setswana-speaking participants.

\subsection{Tshivenda-speaking participants}

The participants from the Tshivenda-speaking group defined interpreting as ndi $u$ amba zwo ambiwa nga muambi wa zwi pfukisela kha tshikhuwa u songo engedza kha honoyo mulaedza ('it is to speak what was said by the speaker and convey it into English without adding to what was said in the message' - this English version was given by the group itself). However, the author requested a translation of this phrase from a qualified translator who translated it as "to say what the speaker said and translate it into English without adding anything to the message". The latter definition is similar to that of the IsiNdebele-, Setswana- and IsiXhosa-speaking participants.

\section{Findings}

The findings reveal that court interpreters are interpreting according to their own preferences without using a common model (or several common models) of interpreting. Such a situation could compromise the notion that "justice must be seen to be done" to courtroom participants relying on the services of court interpreters.

The findings indicate that the cognitive teaching approach is beneficial to the training of court interpreters. As far as the workshops are concerned, participants were able to provide not only different, but also similar definitions of what interpreting entails. The definitions provided were the descriptions of the process of interpreting which explain in clear terms what court interpreters actually do. The cognitive approach has also proven its ability in the formulation of models of interpreting. Through this approach, court interpreters are sensitised and helped to understand the processes involved in their task. Once these processes are understood, the chances are better that they will have a clearer sense of their role and, as a result, will perform it more confidently.

However, due to the unclear wording and inconsistent descriptions provided by court interpreters, it is crucial that the judiciary - including other legal officers like lawyers and advocates - be involved in assisting with a clear formulation of the role of court interpreters.

\section{Discussion of the findings}

The teaching approach used during training proved that a cognitive approach to teaching and training court interpreters is very useful in helping them formulate models of interpreting. As stated in the findings, definitions of interpreting with similarities and also differences were 
provided by the various groups, and it would appear that the definitions provided seem to stem from the manner in which the participants were asked to approach the definition of interpreting.

The point of departure of the training - the cognitive process approach - seems to be one of the best teaching methods of training practising court interpreters. This was indicated by the definitions and explanations of interpreting they provided. The approach used during teaching raised their awareness of the process involved in interpreting, and this awareness could guide them in what they need to do when called upon to interpret. This can be seen in the way they had to think carefully about the process involved in interpreting, which was evident during their responses. Such an approach could certainly help shape court interpreters' understanding of their role.

From the participants' responses, some important and unique aspects emerged, indicating totally different approaches to the process of interpreting by South African court interpreters. I refer here to the South African context because the participants were asked to define and describe the phenomenon of interpreting in their South African languages. They defined interpreting in terms of their understanding of communication in the South African context and based on their own perceptions of what they actually do when interpreting. Among the six terms used to define and describe the process of interpreting, the two terms most commonly used were "explain" and "convey", both of which relate to the conduit model. It would appear that the "explaining" and "conveying" of messages is what court interpreters perceive themselves to be doing during their task of interpreting. This is evident from the additional points some participants made to foreground their argument in relation to their definitions and descriptions of what they do when they interpret. It also confirms that court interpreters are the ones who can best explain what they actually do when interpreting, as they are the ones who carry out the process.

\section{Recommendations}

Being aware of different models of interpreting is important in helping court interpreters understand their task, and they should be taught about these models. This will help them to conceptualise the interpreting process, as demonstrated in the discussion of the findings, which they could afterwards put into practice. This study therefore recommends that models of interpreting be formulated using an approach similar to that used during the workshops discussed in this article, and that these models are not blindly imposed on court interpreters. The formulation of models of interpreting by court interpreters themselves would make sense, as they are in the best position to describe the process which they carry out. The study also recommends that further research be conducted on the area of models of interpreting, as it forms the core of interpreting practice. It is also crucial that awareness of different models of interpreting be made part of the training of court interpreters.

\section{Conclusion}

The findings of the workshops for the training of court interpreters employed by the Department of Justice and Constitutional Development reveal that court interpreters do not receive training on the models of interpreting. The workshop participants provided different definitions and descriptions of what the process of interpreting entails. Through an approach employed during the workshops which entailed making court interpreters reflect critically on their interpreting role, 
this study has indicated that cognitive teaching could be one of the best approaches in the teaching and training of court interpreters in South Africa. Such an approach raises awareness and understanding of the interpreting task. It would be highly beneficial to include learning about different models of interpreting as part of the training of court interpreters.

\section{Acknowledgements}

My gratitude goes to Ms Tiny Modishane, the Deputy Director HRD, at the Limpopo Regional Office of the Department of Justice and Constitutional Development in Polokwane. She wholeheartedly supported my workshop, entitled "Become a Language Interpreter", for the training of court interpreters which was conducted from 26-28 September 2011 in that region. Let me extend my gratitude to Mr Maleye Shaku, the Senior Training Officer, who worked tirelessly together with Ms Modishane to ensure that court interpreters received the correct and full information regarding the workshop. Without your valuable support, the workshop would have not been a success. I also express my appreciation to all court interpreters who attended the workshop. Your participation and comments contributed immensely to the writing of this article. A huge amount of gratitude goes to Dr Felicity Horne, my former colleague who retired from the Department of English Studies at Unisa, and who not only edited my manuscript, but also made substantive suggestions about the content. I dedicate this article to all court interpreters in South Africa.

\section{References}

Angelelli, C.V. 2004. Revisiting the interpreter's role: A study of conference, court, and medical interpreters in Canada and United States. Amsterdam: John Benjamins.

Bar-Tzur, D. 1999. Integrating the interpreting service models. Available online: www.theinterpretersfriend.com/misc/models.html (Accessed 20 February 2006).

Berk-Seligson, S. 2006. Court interpreting. Nashville: Vanderbilt University.

Clifford, A. 2004. Is fidelity ethical? The social role of the healthcare interpreter. TTR: traduction, terminologie, rédaction 17(2): 89-114.

Cokely, D. 1992. Interpretation: Towards a social model. Burtonsville, MD: Linstok Press.

Colonomos, B. 1992. Process in interpreting and transliterating: Making them work for you. Teleclass provided by RSA Region VIII Interpreter Training Project. Denver, CO: Distance Opportunity for Interpreter Training Center, Front Range Community College.

Du Plessis, T. 1997. Interpreting in South Africa. Acta Varia (3): 1-9.

Eighinger, L. and B. Karlin. 2001. Feminist-relational approach: A social construct for event management. Available online: http://www.signs-of-development.org/website/Letters.html (Accessed 11 February 2001).

Gonzalez, R.D., V.F. Vasquez and H. Mikkelson. 1991. Fundamentals of court interpretation: Theory, policy and practice. Durham, NC: Carolina Academic Press. 
Hale, S. 2008. Controversies over the role of court interpreter. In C. Valero-Garcés and A. Martin (Eds.) Crossing borders in court interpreting: Definitions and dilemmas. Amsterdam/Philadelphia: John Benjamins. pp. 99-121.

Kelly, A. 2000. Cultural parameters for interpreters in the courtroom. In R.P. Roberts, S.E. Carr, D. Abraham and A. Darfour (Eds.) The critical link 2: Interpreters in the community. Selected papers from $2^{\text {nd }}$ International Conference on Interpreting in Legal, Health and Social Services Settings. Amsterdam/Philadelphia: John Benjamins. pp. 131-148.

Kondo, M. 1990. What conference interpreters should not be expected to do. The Interpreters' Newsletter 3: 59-65.

Lakoff, G. and M. Johnson. 1980. Metaphors we live by. Chicago: University of Chicago Press.

Laster, K. and V. Taylor. 1995. The compromised "conduit": Conflicting perceptions of legal interpreters. Criminology Australia 6(4): 9-14.

Lebese, S. 2011. A pilot study on the undefined role of court interpreters in South Africa. Southern African Linguistic and Applied Language Studies 29(3): 343-353.

Lee, J. 2009. Conflicting views on court interpreting examined through surveys of legal professionals and court interpreters. Interpreting 11(1): 35-56.

Lesch, H.M. 2011. In search of an interpreting research methodology for Africa. Southern African Linguistics and Applied Language Studies 29: 359-371.

Moeketsi, R.H. 1999. Discourse in a multilingual and multicultural courtroom: A court interpreter's guide. Pretoria: Van Schaik.

Morris, R. 1999. The gum syndrome: Predicaments in court interpreting. Forensic Linguistics 6(1): 6-29.

Mullamaa, K. 2009. Towards a dynamic role model of liaison interpreters: Self-descriptions of practices in Estonia. New Voices in Translation Studies 5: 46-62.

National Association of Judiciary Interpreters and Translators (NAJIT). 2005. Code of ethics and professional responsibilities. Available online: http://www.najit.org/ethics.html (Accessed 20 December 2005).

Padilla, P., M.T. Bajo and F. Padilla. 1999. Proposal for a cognitive theory of translation and interpreting: A methodology for future empirical research. The Interpreters' Newsletter 9: 61-78.

Pöchhacker, F. 2010a. Introducing interpreting studies. London: Routledge.

Pöchhacker, F. 2010b. The role of research in interpreter education. Translation \& Interpreting 2(1): $1-10$.

Renmen, R.N. 1999. Helping, fixing or serving? Shambalala Sun, September 1999. 
Roy, C. 1993. The problem with definitions, descriptions and the role metaphors of interpreters. Journal of Interpretation 6(1): 127-154.

Setton, R. 2013. Models of interpreting. The Encyclopedia of Applied Linguistics 15(2): 365-381.

Steytler, N.C. 1993. Implementing language rights in court: The role of the court interpreter. South African Journal on Human Rights 9(2): 205-222.

Toury, G. 1980. In search of a theory of translation. Jerusalem: Academic Press.

Wilcox, S. and B. Shaffer. 2005. Towards a cognitive model of interpreting. In T. Janzen (Ed.) Topics in signed language interpreting. Amsterdam/Philadelphia: John Benjamins. pp. 135-164. 